\title{
High-Resolution Modeling of Uplift Landscapes can Inform Micrositing of Wind Turbines for Soaring Raptors
}

\author{
Frank Hanssen $^{1} \cdot$ Roel May ${ }^{1}{ }^{1} \cdot$ Torgeir Nygård $^{1}$
}

Received: 20 February 2020 / Accepted: 13 June 2020 / Published online: 24 June 2020

(c) The Author(s) 2020

\begin{abstract}
Collision risk of soaring birds is partly associated with updrafts to which they are attracted. To identify the risk-enhancing landscape features, a micrositing tool was developed to model orographic and thermal updraft velocities from highresolution remote sensing data. The tool was applied to the island of Hitra, and validated using GPS-tracked white-tailed eagles (Haliaeetus albicilla). Resource selection functions predicted that eagles preferred ridges with high orographic uplift, especially at flight altitudes within the rotor-swept zone $(40-110 \mathrm{~m})$. Flight activity was negatively associated with the widely distributed areas with high thermal uplift at lower flight altitudes $(<110 \mathrm{~m})$. Both the existing wind-power plant and planned extension are placed at locations rendering maximum orographic updraft velocities around the minimum sink rate for white-tailed eagles $(0.75 \mathrm{~m} / \mathrm{s})$ but slightly higher thermal updraft velocities. The tool can contribute to improve micrositing of wind turbines to reduce the environmental impacts, especially for soaring raptors.
\end{abstract}

Keywords White-tailed eagle $\cdot$ Norway $\cdot$ Thermal and orographic updraf $\cdot$ GIS $\cdot$ Remote sensing

\section{Introduction}

While the development of wind energy contributes to reducing greenhouse gas emissions, this may simultaneously negatively affect wildlife, particularly birds and bats. Internationally, there is a particular concern about birds colliding with wind turbines (Langston 2013; Marques et al. 2014; Schuster et al. 2015). Soaring bird species, such as raptors, are known to be specifically vulnerable for collision with wind turbines (Ferrer et al. 2012; Wang et al. 2015). Collision risk of soaring raptors is associated with species-specific flight behavior, topographical features, and seasonal abundances; however, the exact mechanisms of collision susceptibility remain unclear (Barrios and Rodriguez 2004; Dahl et al. 2013; de Lucas et al. 2008). At windpower plants, that have already incurred multiple raptor mortalities, these collisions have often clustered around a limited number of turbines (Barrios and Rodriguez 2004, 2007; Ralston Paton et al. 2017). Effective mitigation

Roel May

roel.may@nina.no

1 Norwegian Institute for Nature Research, P.O. 5685 Torgarden, 7485 Trondheim, Norway actions hereby require prediction of the expected area utilization of present birdlife for the identification of sites with higher expected collision risk.

Following the rationale of the mitigation hierarchy, mitigation measures implemented early in the development process should be prioritized (May 2017). Promising approaches to facilitate "bird-friendly" micrositing of turbines during the preconstruction design, and detailed planning phase may support locating wind turbines at sites that pose minimal risk to birds (Jenkins et al. 2015; May 2017). Several studies have attempted to predict locations with increased collision risk for raptors using resource selection functions based on telemetry data (Miller et al. 2014) or simulated horizontal wind flows across the topography in an wind tunnel (de Lucas et al. 2012). However, the first approach requires detailed knowledge on movement patterns in species at risk, while the second approach requires access to a boundary layer wind tunnel to be able to predict potential risk at a planned wind energy site. At the early planning phase, such data sources or experimental infrastructure are however most likely not available.

Many bird species (especially raptors) are attracted to vertical air currents or updrafts, which allows for energysaving soaring flight (Harel et al. 2016a; Hedenström and Alerstam 1995; Shamoun-Baranes et al. 2003, 2016). Updrafts induced by the landscape occur when solar heating 
of land cover types with specific spectral reflectance characteristics creates vertical air fluxes (thermal updrafts), and when horizontal wind is forced upwards by elevated topography (orographic updrafts) (Bohrer et al. 2012). The birds' ability to exploit these updrafts (their uplift capacity) is species-specific (Mellone et al. 2012; Shamoun-Baranes et al. 2003). Updraft modeling may therefore provide a proxy for identifying sites with potentially increased risk of collision for soaring birds.

Several attempts have been made to estimate the location and intensity of such updrafts at different spatial resolutions utilizing GIS, remote sensing, weather forecast models, and computational fluid dynamic models (Bohrer et al. 2012; Harel et al. 2016b; Shamoun-Baranes et al. 2016; Shannon et al. 2003; Shepard et al. 2016; Treep et al. 2016). Estimating thermal updrafts is very complex due to the chaotic nature of turbulence governing the atmosphere (Reddy et al. 2016). Bohrer et al. (2012) estimated thermal updraft velocity from the North American Regional Reanalysis (NARR) model-observation hybrid dataset $(32 \times 32 \mathrm{~km})$. Shannon et al. (2003) and Harel et al. (2016b) refer to the estimation of thermals based on weather forecast models such as the European Center for Medium Range Weather Forecast model (ECMWF, $12.5 \times 12.5 \mathrm{~km}$ ).

With the exception of Treep et al. (2016) and Shepard et al. (2016), the above-mentioned attempts were based on spatial datasets with coarse resolutions $(>1 \mathrm{~km})$. Treep et al. (2016) used a re-analyzed ECMWF model with a spatial resolution of $300 \mathrm{~m}$ and a digital terrain model (DTM) with a spatial resolution of $90 \mathrm{~m}$. Shepard et al. (2016) used a LIDAR-based DTM with a spatial resolution of $2 \mathrm{~m}$ and a computational fluid dynamic (CFD) model with a spatial resolution of $1 \mathrm{~m}$. Still, to enable applying these models for siting of wind turbines, the model should be spatially explicit with 1) a relative fine spatial resolution and 2) have the capability of implementing cost-effectively in a preconstruction situation. Weather models (Treep et al. 2016) represent interpolations from meteorological ground stations at coarser spatial resolutions, and therefore do not fully comply to the first requirement. LIDAR-based models (Shepard et al. 2016) will depend upon high-cost laserscanning, and therefore hamper the second requirement.

To support bird-friendly micrositing of turbines, locations with terrain characteristics that attract soaring birds and thereby enhance the risk of collision need to be identified - and consequently avoided - at fine-scale spatial resolutions without requiring collecting site-specific data (May 2017). Scacco et al. (2019) found that static features of the landscape proved to be highly effective in identifying areas suitable for uplifts. Publicly available Landsat 8 imagery enables the quantification of reflected radiation from the surface at a relatively fine spatial resolution of
$100 \mathrm{~m}$. Augmentation with high-resolution DTMs (10 m) allows the fine-scale assessment of risk for soaring raptors for any planned wind energy project. The main objective of this study was therefore to identify the risk-enhancing landscape features by modeling orographic and thermal updraft velocities at such a fine spatial resolution. The updraft calculations were previously validated in Tarifa on the Spanish side of the Strait of Gibraltar (Santos et al. 2017). Here, the methodology was applied and validated in a totally different habitat and environmental conditions, and specifically its merit for micrositing of wind turbines was evaluated. The updraft landscape on the island of Hitra, Norway, was modeled using a combination of Landsat 8 Thermal Band 10 and the Norwegian DTM10 elevation model, including a validation using GPS-tracked whitetailed eagles, Haliaeetus albicilla. The hypothesis was that white-tailed eagles selected locations with increased orographic and thermal updraft velocities that enable soaring flight; thereby enhancing the risk of collision (i.e., through increased exposure). At these northern latitudes selection for sites with thermal uplift were expected to be significantly lower than for sites with orographic uplift, and where white-tailed eagles would rely more on the relatively stronger orographic updrafts in their soaring flight preferences. It was also hypothesized that preference for updraft sites was highest at lower flight altitudes as a means to gain altitude for the eagles (c.f. Duerr et al. 2012). Finally, a preliminary evaluation was performed on the effect of maximum updraft velocities on the collision rate at wind turbines on the island. If these expectations hold, maximum orographic and thermal updraft velocities provide the cost-effective proxies for risky locations for soaring birds. Following a precautionary approach, avoiding such locations will be important information for bird-friendly micrositing of wind turbines.

\section{Methodology}

\section{Study Site}

This study was implemented on the Hitra Island $\left(63.60^{\circ} \mathrm{N}\right.$, $8.65^{\circ}$ E) in Trøndelag County, Norway (Fig. 1). Hitra has a typical coastal climate with relatively temperate springs/ summers and mild autumns/winters dominated by strong winds and heavy rainfalls. With its land area of $680.4 \mathrm{~km}^{2}$, Hitra and its surrounding archipelago provides an important habitat for white-tailed eagles (Dahl et al. 2012; May et al. 2013). The terrain on Hitra is relatively rugged with 16 mountain peaks (the highest peak being $345 \mathrm{~m}$ above sea level). The land cover on Hitra is comprised of lakes and rivers $(5 \%)$, bogs $(16 \%)$, forests $(29 \%)$, farmland $(2 \%)$, and 
Fig. 1 Estimated maximum orographic (top panel) and thermal (lower panel) updrafts velocities $(\mathrm{m} / \mathrm{s})$ across seasons above the minimum required sink rate required by whitetailed eagles $(0.75 \mathrm{~m} / \mathrm{s})$ to be able to glide on upward moving air currents on the island of Hitra, Norway. The middle panel shows proportion of land area providing updrafts (in $\%$ of total for each updraft category separately) across updraft velocities ranging from 0.75 to $9.88 \mathrm{~m} / \mathrm{s}$ for orographic (red bars) and thermal updrafts (blue bars). The existing wind-power plant constructed in 2004 and planned extension in 2019 are respectively outlined in black and green
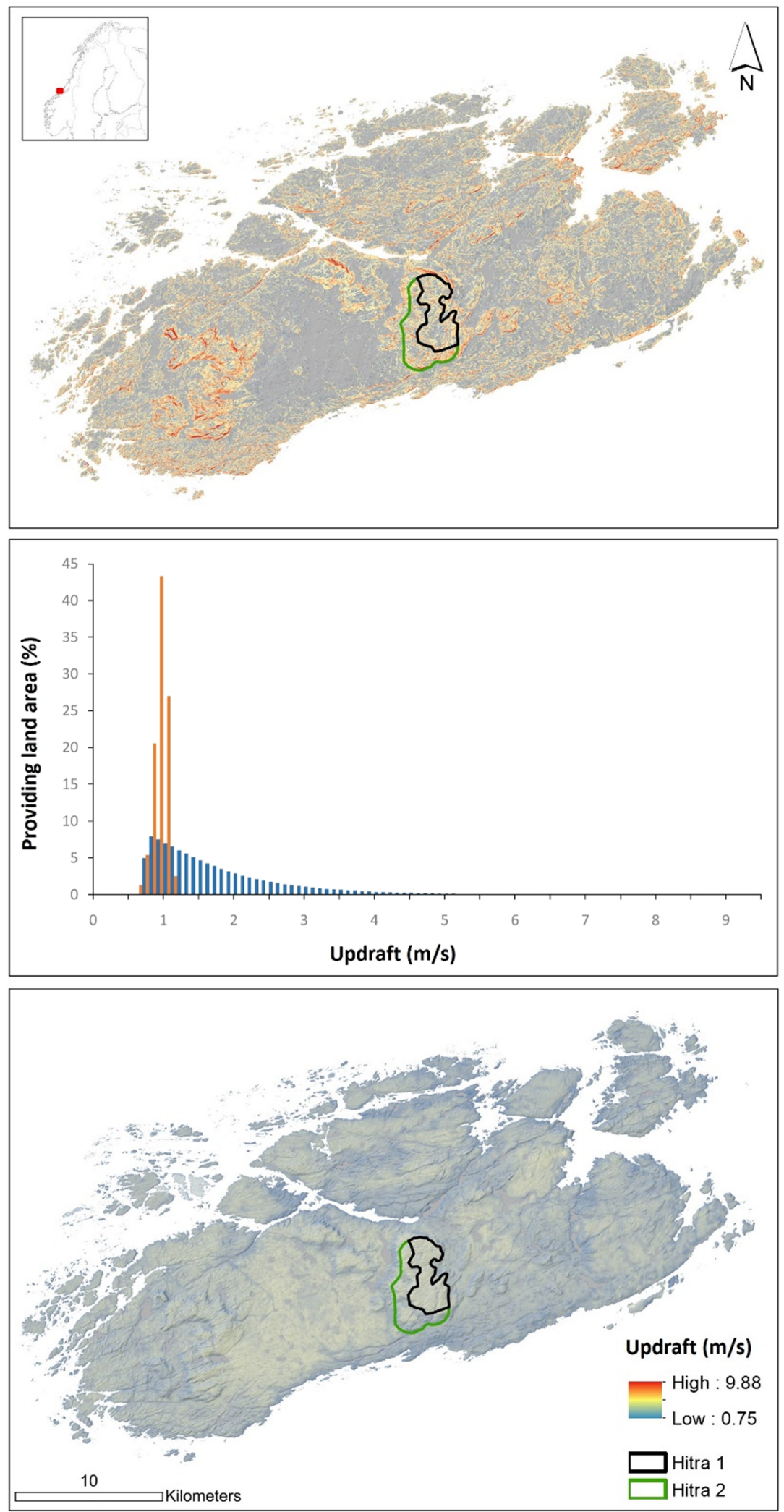

open areas and settlements (48\%). At Eldsfjellet, a mountain area in the central part of Hitra, a wind-power plant was constructed in 2004 consisting of 24 turbines (55 MW installed capacity). In 2019, this wind-power plant will be expanded with another 26 turbines (additional 94 MW installed capacity). 


\section{Modeling the Updraft Landscape}

\section{Estimation of thermal updrafts}

The thermal updraft velocity was estimated at a $100 \times 100 \mathrm{~m}$ spatial resolution using a combination of Landsat 8 imagery, climate variables and atmospheric constants. The thermal updraft velocity was estimated using the standard atmospheric scaling coefficient called the "free connectivity scaling velocity" or the Deardorrf velocity $\left(w^{*}\right)$ according to Bohrer et al. (2012):

$$
w^{*}=\left[\frac{g \cdot z \cdot H}{\theta}\right]^{\frac{1}{3}},
$$

with $g$ as the gravitational acceleration (set to $9.8 \mathrm{~m} / \mathrm{s}^{2}$ ), $z$ as the flight altitude in the rotor swept zone (set to $80 \mathrm{~m}$ a.g.l., assumed to be within the atmospheric boundary layer), $H$ as the surface sensible heat flux measured in $\mathrm{W} / \mathrm{m}^{2}$ and $\theta$ as the potential temperature measured in Kelvin. The surface sensible heat flux $(H)$ describes how thermal energy is transferred from the ground surface to the atmosphere through conduction and convection ( $\mathrm{Hu}$ et al. 1999):

$H=p \cdot c_{\mathrm{p}} \frac{\left(T_{\mathrm{s}}-T_{\mathrm{a}}\right)}{r_{\mathrm{a}}}$,

with $p$ as the sea level air density (set to $1.225 \mathrm{~kg} / \mathrm{m}^{3}$ ), $c_{\mathrm{p}}$ as the isobaric mass heat capacity (set to $1.0035 \mathrm{~J} / \mathrm{kg} / \mathrm{K}$ ), $r_{\mathrm{a}}$ as the aerodynamic resistance for an approximated grassland surface (set to a factor of 208 divided by the horizontal wind speed at $2 \mathrm{~m}$ height, according to Allen et al. 1998), and $T_{\mathrm{s}}$ and $T_{\mathrm{a}}$ as, respectively, the land surface and mean air temperature given in Kelvin. The potential temperature $(\theta)$ from Eq. 1 describes the temperature of an unsaturated part of dry air when brought adiabatically and reversibly from its initial state and to a standard pressure (Stull 1988):

$\theta=T_{\mathrm{a}}\left(\frac{p_{0}}{p}\right)^{\mathrm{k}}$

with $T_{\mathrm{a}}$ is the mean air temperature given in Kelvin, $p_{0}$ is the sea level standard air pressure given in millibar, $p$ is the atmospheric boundary layer (ABL) air pressure at $1 \mathrm{~km}$ a.s. 1. (set to 898.7457 millibar), and $k$ as the Poisson constant for dry air (set to 0.2854 ).

\section{Estimation of orographic updrafts}

The orographic updraft velocity was estimated at $10 \times 10 \mathrm{~m}$ spatial resolution based on climate variables and a highresolution DTM downloaded from the Norwegian
Geospatial Data Catalog (www.geonorge.no). The orographic updraft velocity $\left(w_{0}\right)$ is a function of horizontal wind speed ( $v$ in $\mathrm{m} / \mathrm{s}$ ) forced upwards by elevated topography and was estimated according to Brandes and Ombalski (2004) and Bohrer et al. (2012):

$w_{0}=v \cdot C_{\alpha}$.

The updraft coefficient $\left(C_{\alpha}\right)$ was calculated as a function of the horizontal wind direction $(\alpha)$ in degrees, and the terrain slope $(\theta)$ and aspect $(\beta)$ angle in degrees calculated from the DTM using the ArcGIS slope and Aspect tools:

$$
C_{\alpha}=\operatorname{Sin}(\theta) \cdot \operatorname{Cos}(\alpha-\beta) \text {. }
$$

\section{Mapping the seasonal updraft landscape}

To compare the seasonal differences in the updraft landscape of Hitra, thermal, and orographic uplift velocities were modeled for one snow-free and cloud-free day for each year from 2013 to 2016 and during the following predefined seasonal periods: January-March (winter), April-June (spring/early summer), July-September (late summer/fall), and October-December (late fall/early winter). As Landsat 8 was launched in February 13th 2013, the study period was restricted to the last 9 months of 2013 (there were no suitable Landsat 8 images for January-March; $n=3$ ), 2014 ( $n=4), 2015$ ( $n=4)$, and 2016 (until to the end of the study period mid-September 2016, $n=3$ ). Given the limited number of available relatively cloud-free images in the different seasonal periods, each image was visually inspected and selected as near mid-season as possible to represent each seasonal period, totaling 14 images.

Landsat 8 Operational Land Imager (OLI) and Thermal Infrared Sensor (TIRS) imagery (Thermal Band 10) were downloaded from the United States Geological Survey archive (United States Geological Survey 2017). The Landsat 8 Quality Assessment Band (BQA) provides pixelby-pixel information of detected details such as terrain occlusion, water, vegetation, snow, ice, aerosols, clouds, and cloud shadows to mention some. To identify where these characteristics occurred in a given Landsat 8 image, the open source tool "Landsat Land Data Operational Product Evaluation Tool (LDOPE)" (Borak et al. 2002) was used to derive quality issue masks from the BQA-band. Atmospheric correction data (atmospheric transmission constant, upwelling, and downwelling radiance constants; Table 1) for the downloaded Landsat 8 images was calculated with the atmospheric correction parameter calculator (Barsi et al. 2003, 2005). The land surface temperature $\left(T_{\mathrm{s}}\right)$ was calculated in ESRI ArcGIS Advanced 10.3 using the Python algorithms for automated mapping of land surface temperature from Landsat 8 images (Walawender et al. 2012). These algorithms are incorporated in the thermal 


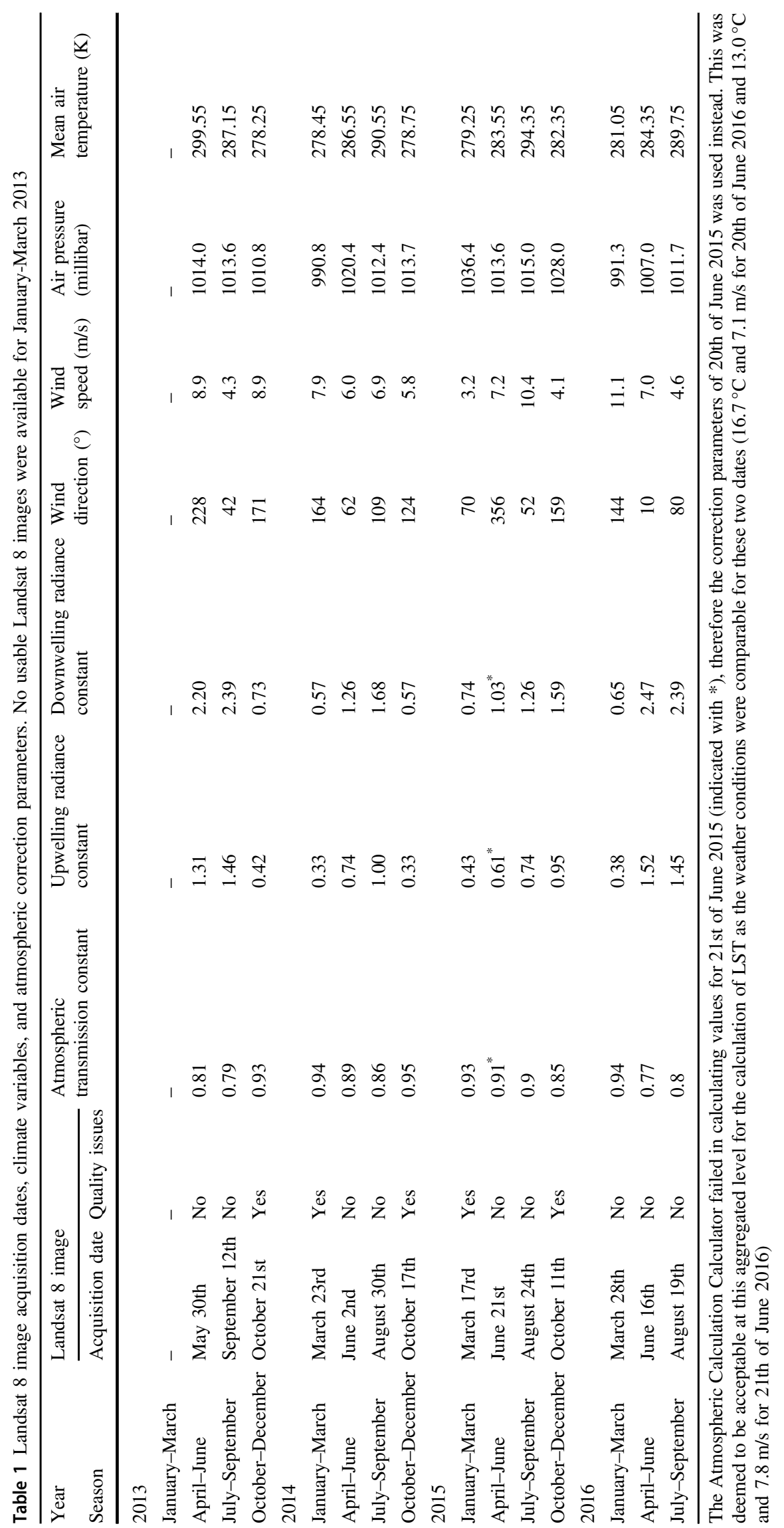


updraft tool, so that it automatically requesting the required atmospheric constants when running the tool. Further details on the exact methodology for calculating LST are presented in Walawender et al. (2012).

For each seasonal representative image, climate variables (mean air temperature $\left(T_{\mathrm{a}}\right)$, horizontal wind speed $(v)$, wind direction $(\alpha)$, sea level standard air pressure $\left.\left(p_{0}\right)\right)$ measured at the Sandstad II weather station at Hitra $\left(63.52^{\circ} \mathrm{N}, 9.11^{\circ}\right.$ E; $13 \mathrm{~m}$ above sea level) were downloaded from the Norwegian Meteorological Survey (Norwegian Meteorological Survey 2017) for the acquisition date and the required atmospheric correction parameters were calculated with the atmospheric correction parameter calculator as described above (Table 1). All modeling of the updraft landscape of Hitra, given by its thermal and orographic updraft potential, was done in ESRI ArcGIS 10.3 ModelBuilder (model provided as Supplementary Material) using a combination of a high-resolution DTM, remote sensing imagery, climate data, and atmospheric constants.

\section{Forecasting Risk-Enhancing Terrain for Bird Collisions with Wind Turbines}

\section{Calculation of minimum sink speed for white-tailed eagles}

Different bird species have different wing morphology and mass-to-wing area ratio which affect their flight. These characteristics will influence species-specific flight strategies, and the different bird species' capability to exploit orographic and thermal uplift as they traverse the landscape. Birds need to overcome drag to enable gliding flight, which The open source Flight program developed by Pennycuick (2008) was used to determine the minimum requirements of white-tailed eagles for taking advantage of uplift in soaring flight activities (i.e., based on the glide polar). Based on the species' mass (4.8 kg), morphology (wingspan: $2.2 \mathrm{~m}$; wing area: $\left.0.615 \mathrm{~m}^{2}\right)$ and air density $\left(1.216 \mathrm{~kg} / \mathrm{m}^{3}\right.$ at $80 \mathrm{~m}$ above sea level), a minimum sink rate of $0.75 \mathrm{~m} / \mathrm{s}$ for white-tailed eagles was calculated which represents the minimum uplift required to avoid sinking downwards in upward air currents. In ridge soaring conditions, soaring flight is typically used to cover the maximum distance and would therefore be flown at best glide velocity, which is slightly higher than the minimum sink velocity and will result in a slightly higher sink rate $(0.93 \mathrm{~m} / \mathrm{s})$. The lower minimum sink velocity was used as a threshold to assess the spatial extent of areas with updraft velocities enabling soaring, and to compare to the modeling outcomes (see below).

\section{Predicting white-tailed eagle updraft preferences}

An assessment was performed on whether locations with higher orographic and/or thermal updraft velocities pose increased the potential risk of collisions with wind turbines (when sited at such locations) for white-tailed eagles. Between 2003 and 2016, 71 white-tailed eagle nestlings were equipped on the neighboring island of Smøla with GPS backpack tracking devices (Microwave Telemetry, Inc., Columbia, MD, USA; S.D. $\pm 11 \mathrm{~m}$ ) rendering data on their movements (Watson et al. 2018). Capture and handling of birds was approved by the Norwegian Environment Agency and the Norwegian Animal Research Authority. The GPS tracking devices were programmed differently per individual with regard to the amount of daily positions acquired (range: 1-24 per day; Nygård et al. 2010). Many of these birds also frequented the island of Hitra. The reason for executing the study at Hitra, was that Smøla has no topography of significance and thereby lacking orographic uplift potential. Because most of the GPS tracking devices were solar-powered, fewer data were obtained during the dark winter months. In the analysis, only in-flight positions within the period 2013-2016 were included with instantaneous speed (i.e., speed when the fix was acquired) larger than $0 \mathrm{~m} / \mathrm{s}$ and GPS-measured altitude above ground level (a.g.l.) (Poessel et al. 2018). For all included positions, flight altitude was calculated by subtracting the elevation at ground level (DTM 10, $\pm 2-6 \mathrm{~m}$ ) from the GPS-measured altitude (S.D. $\pm 20 \mathrm{~m}$ ). Flight altitude was thereafter grouped into three categories: below the rotor-swept zone (RSZ) (<40 m), within RSZ (40-110 m), and above RSZ (>110 m) (Fig. 2).

The probability of presence of an individual in flight was modeled as a binomial variable $(1=$ GPS positions and $0=$ pseudo-absences from random points, respectively) given as a function of the orographic and thermal updraft values. For each position, five random positions (pseudo-absences) were calculated and assigned the same temporal, altitude, and individual information to analyze the differences between actual positions (GPS positions) and available positions (random points generated using the ArcGIS tool "Create random points"). Random positions were distributed throughout the island indicating availability, as white-tailed eagles are known to be able to cover large distances and thus could at any time have traversed the island and surroundings (Nygård et al. 2010). To avoid any spurious results due to potential updraft influences from the surrounding ocean areas, all positions within $100 \mathrm{~m}$ of the coastline were removed. The seasonal orographic and thermal updraft values from the 14 season-specific and yearspecific datasets were extracted for both the GPS and the random positions assuming the chosen dates (see Table 1) as being representative for all positions within that season and year, to obtain a dataset of used positions with dates and updraft associations and pseudo-absence positions with the same dates and their updraft associations. Only positions with valid updraft values were included, excluding locations 

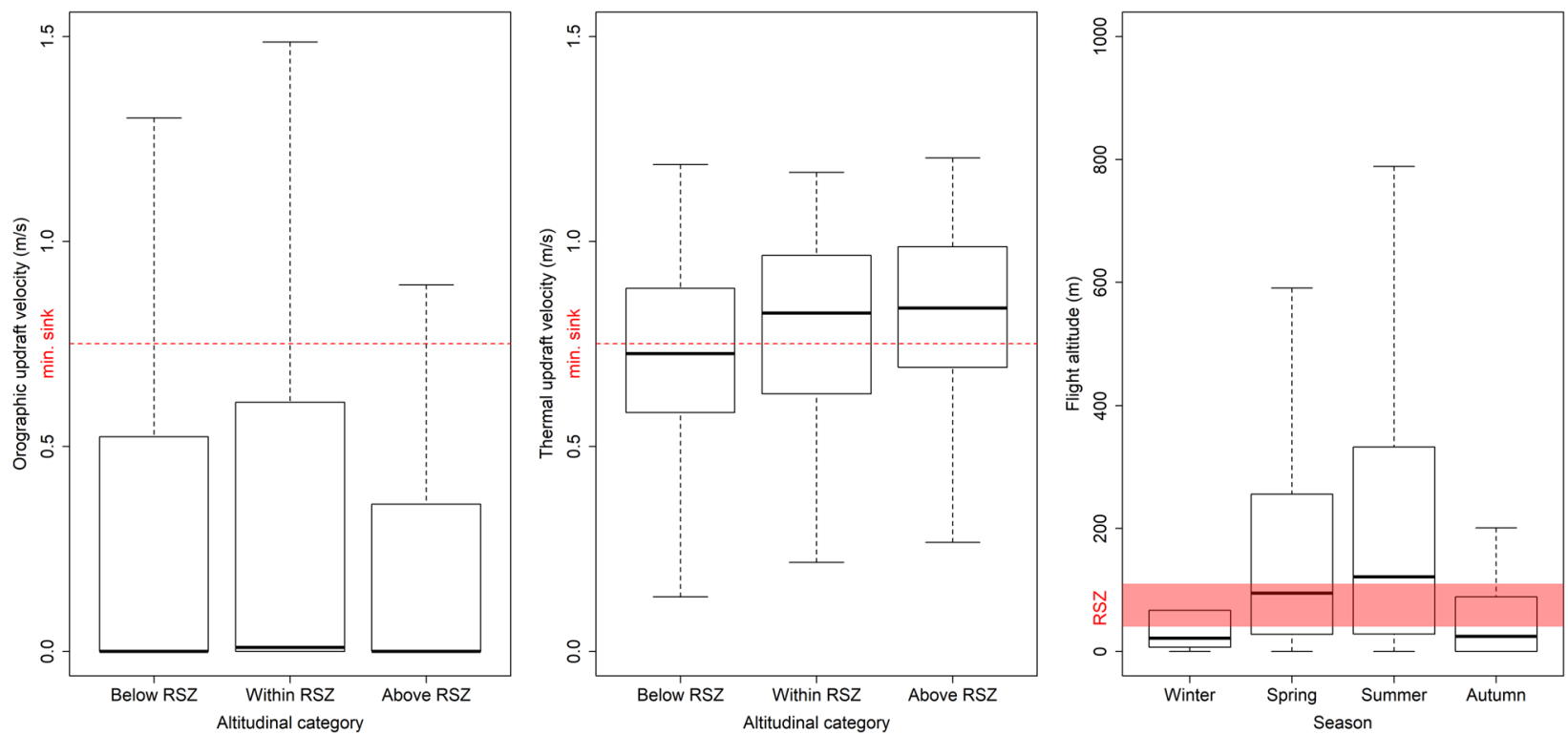

Fig. 2 Orographic and thermal updraft associations and seasonal variation in flight altitude on the island of Hitra, for GPS positions of white-tailed eagles. The boxplots show the median (black line), 75 (white box) and 95 (whiskers) percentiles. The two left-most panels include the minimum sink threshold speed for white-tailed eagles $(0.75 \mathrm{~m} / \mathrm{s}$; red dotted line). The right-most panel includes the altitudinal range falling within the rotor-swept zone (RSZ)

hour-of-the-day nested within individuals (1IInd/Hour) using the glmer function of the lme4 library (Bates et al. 2015). In total 16 a priori models were compared, assessing the single and additive effects of orographic and/or thermal updraft velocities on the probability of presence, based on the Akaike Information Criterion corrected for small sample sizes (AICc). To assess whether the whitetailed eagles' response to updrafts was affected by either flight altitude categories or seasonal period, these four basic models (intercept, two single and one additive model) were considered as well as models including first order interactions with flight altitude categories or seasonal periods (Table 2). Model performance of the most parsimonious model (the simplest model with the least assumptions and variables but with greatest explanatory power) was assessed using 10-fold cross-validation employing an adjusted kxvlmer function (Wiens et al. 2008) to evaluate glmer models (kxvglmer). This was done by training the model on a random sample of $90 \%$ of the data and testing the goodness-of-fit of the remaining $10 \%$ using Pearson correlation within ten randomly assigned frequency bins. To assess the accuracy of the predictive power of the best model influence-curve-based confidence intervals were calculated for cross-validated area under the curve (AUC) estimates using the ci.cvAUC function with ten folds of the cvAUC library (LeDell et al. 2015). Effect sizes for the different covariates are indicated by the $F$ statistic. All modeling was scripted (provided as Supplementary Material) in the statistical software program R version 3.2.2 (R Core Team 2015). of seasonal period nested within year (1/Year/Season) and 
Table 2 Model parsimony for the a priori models assessing whitetailed eagles' probability of presence for locations with orographic (O) and/or thermal (T) uplift, also including first-order interactions with flight altitude (F) and/or seasonal period (S)

\begin{tabular}{lrlr}
\hline Model & df & AICc & $\Delta$ AICc \\
\hline $\mathrm{O} * \mathrm{~F}+\mathrm{T} * \mathrm{~F}$ & 13 & $14,321.2$ & 0.0 \\
$\mathrm{O} * \mathrm{~S}+\mathrm{T} * \mathrm{~F}$ & 17 & $14,329.0$ & 7.8 \\
$\mathrm{O}+\mathrm{T} * \mathrm{~F}$ & 11 & $14,340.1$ & 18.8 \\
$\mathrm{O} * \mathrm{~F}+\mathrm{T} * \mathrm{~S}$ & 17 & $14,385.7$ & 64.5 \\
$\mathrm{O} * \mathrm{~F}+\mathrm{T}$ & 11 & $14,389.5$ & 68.3 \\
$\mathrm{O} * \mathrm{~F}$ & 10 & $14,416.3$ & 95.1 \\
$\mathrm{~T} * \mathrm{~F}$ & 10 & $14,417.5$ & 96.3 \\
$\mathrm{O} * \mathrm{~S}+\mathrm{T} * \mathrm{~S}$ & 16 & $14,442.1$ & 120.8 \\
$\mathrm{O} * \mathrm{~S}+\mathrm{T}$ & 13 & $14,446.5$ & 125.2 \\
$\mathrm{O}+\mathrm{T} * \mathrm{~S}$ & 13 & $14,462.8$ & 141.6 \\
$\mathrm{O}+\mathrm{T}$ & 7 & $14,464.6$ & 143.4 \\
$\mathrm{O} * \mathrm{~S}$ & 12 & $14,479.3$ & 158.0 \\
$\mathrm{O}$ & 6 & $14,493.9$ & 172.6 \\
$\mathrm{~T}$ & 6 & $14,549.6$ & 228.4 \\
$\mathrm{~T} * \mathrm{~S}$ & 12 & $14,549.7$ & 228.5 \\
Intercept & 5 & $14,581.1$ & 259.8 \\
\hline
\end{tabular}

Model parsimony is based on the Akaike Information Criterion corrected for small sample sizes (AICc)

\section{Evaluation of potential collision risk at wind turbines}

Finally, the maximum orographic and thermal updraft velocities were extracted for the 24 currently installed wind turbines (Hitra I) as well as for the planned sites for the 26 wind turbines still to be constructed (Hitra II) (SAE Vind 2010) to assess potential collision risk at those sites (Fig. 1). Ten white-tailed eagles are known to have collided at turbines in Hitra I (between August 2006 and June 2016), however there have not been executed intensive searches for collision victims. This assessment should therefore solely be considered as a mapping of potential risk at appropriate turbine sites.

\section{Results}

Seasonal orographic and thermal updraft velocity maps were estimated for the entire island for the selected dates in Table 1. The estimated thermal updraft velocities ranged from 0 to $1.28 \mathrm{~m} / \mathrm{s}$ and the estimated orographic updraft velocities ranged from 0 to $9.89 \mathrm{~m} / \mathrm{s}$. White-tailed eagles require an uplift velocity above $0.75 \mathrm{~m} / \mathrm{s}$ (minimum sink rate) to take advantage of the updrafts in their soaring flight activities. When using this threshold value to segment the maximum updraft maps across seasons, potential thermal soaring areas as well as potential ridge-lift areas available for white-tailed eagles can be identified (Fig. 1). The spatial distribution of thermal uplift areas was significantly more spatially homogenous than the small and fragmented orographic uplift areas. The orographic uplift patches along hills and ridges provide pockets of stronger orographic updraft velocities compared to the relatively weaker updraft velocities in the thermal uplift areas. $93.6 \%\left(637 \mathrm{~km}^{2}\right)$ of the total land area of Hitra provide thermal updraft velocities $>0.75 \mathrm{~m} / \mathrm{s}$, whereas only $53.9 \%\left(366.6 \mathrm{~km}^{2}\right)$ provide orographic updraft velocities $>0.75 \mathrm{~m} / \mathrm{s}$.

Altogether 16 birds were represented in the dataset (2759 GPS positions and 12,882 random positions). Because the GPS devices were solar-powered, the number of GPS positions varied by season (winter $<1 \%$, spring $42 \%$, summer $54 \%$, and autumn $4 \%$ ). In flight, the eagles spent $31 \%$ of their time below RSZ, $20 \%$ within RSZ and 49\% above RSZ. Flight altitude (log-transformed) of GPS positions varied significantly by seasonal period ( $F=5.68, P<0.001$; Fig. 2$)$ with higher flight altitude during spring compared to winter. However, this result should be interpreted with caution. Flight altitude of GPS positions increased with thermal updraft velocities, but not orographic updrafts (respectively: $F=27.45, P<0.001$ and $F=0.46, P=0.496$; Fig. 2).

The additive effects of orographic and thermal updraft velocities in interaction with flight altitude rendered the most parsimonious model in explaining selection probability (Table 2, AICc $=14,321.2$ ). The probability of presence of flying white-tailed eagles in this model (crossvalidation: $\bar{r}=0.855, P=0.004$; AUC $0.578 \pm 0.006$ S.E.) increased significantly with orographic updraft velocity $(z=4.459)$. White-tailed eagles' response to orographic uplift was strongest at flight altitudes within range of the rotor-swept zone (RSZ: 40-110 m a.g.l.; $z=3.920$ ) (Fig. 3). Whereas, the probability of presence was negatively correlated with thermal updraft velocity below RSZ $(z=-9.782)$, it increased with higher flight altitudes ( $z=4.823$ and $z=8.385$ for within and above RSZ, respectively; Fig. 3). Flight altitude category had a significantly stronger effect on probability of presence than seasonal period, given that the highest-ranking models all included flight altitude category (Table 2).

The wind turbines within the Hitra wind-power plant were placed at locations rendering maximum orographic updraft velocities around the minimum sink rate for whitetailed eagles (medians for Hitra I and II: 0.72 and $0.74 \mathrm{~m} / \mathrm{s}$ ) but higher maximum thermal updraft velocities (medians for Hitra I and II, respectively: 1.20 and $1.17 \mathrm{~m} / \mathrm{s}$ ) (Fig. 4). While the turbine sites barely obtained increased orographic updrafts across seasons, thermal updrafts exceeded the minimum sink rate of $0.75 \mathrm{~m} / \mathrm{s}$ in half of the seasons. Turbines where collisions were recorded rendered similar results (medians for orographic and thermal updraft velocities, respectively: 0.78 and $1.20 \mathrm{~m} / \mathrm{s}$ ). The orographic updraft velocities were slightly over the minimum sink speed, however, this was not significantly different 


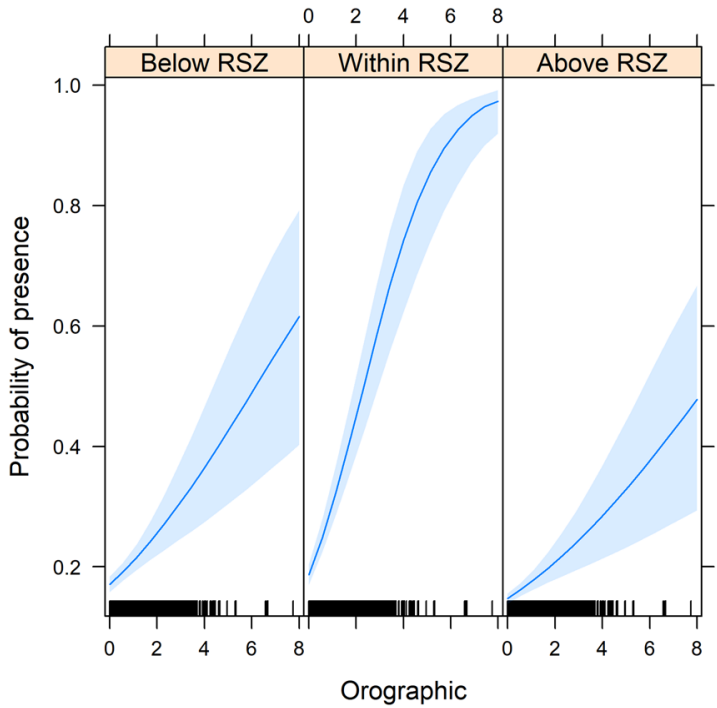

Fig. 3 Partial effects of orographic (left) and thermal (right) updrafts, respectively, in interaction with flight altitude category (below, within and above the rotor-swept zone (RSZ)) on the probability of presence

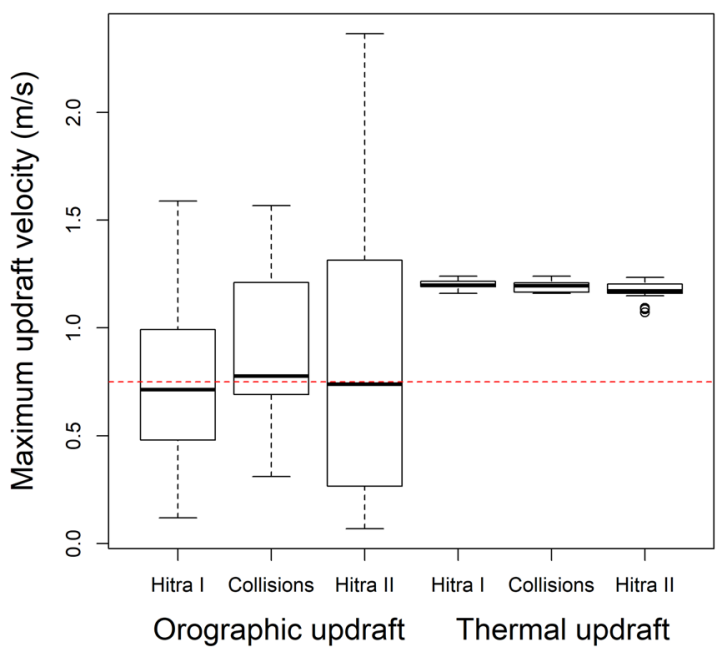

Fig. 4 Updraft velocity $(\mathrm{m} / \mathrm{s})$ and proportion of seasons (Spring 2013-Summer 2016, $N=14$ ) exceeding minimum sink rate for whitetailed eagles $(0.75 \mathrm{~m} / \mathrm{s}$; red dotted line) regarding orographic and thermal updrafts at 24 constructed (Hitra I) and 26 planned (Hitra II)

compared to non-collision turbines (Mann-Whitney $U$-test: $W=50, P=0.576)$.

\section{Discussion}

In this study, the uplift landscape of Hitra was estimated and spatially visualized based on a high-resolution DTM and Landsat 8 Thermal Band 10 imagery. This high-resolution modeling approach refers specifically to the spatial resolution, not the temporal resolution. As the modeling depends on good quality remote imagery (e.g., no ice, snow, and

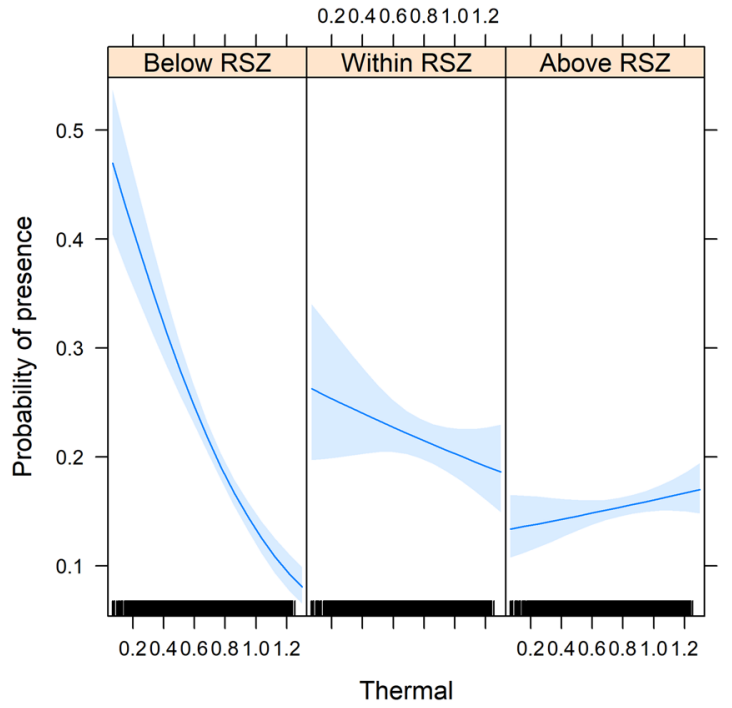

in white-tailed eagles on the island of Hitra. The shaded areas indicate the $95 \%$ confidence interval

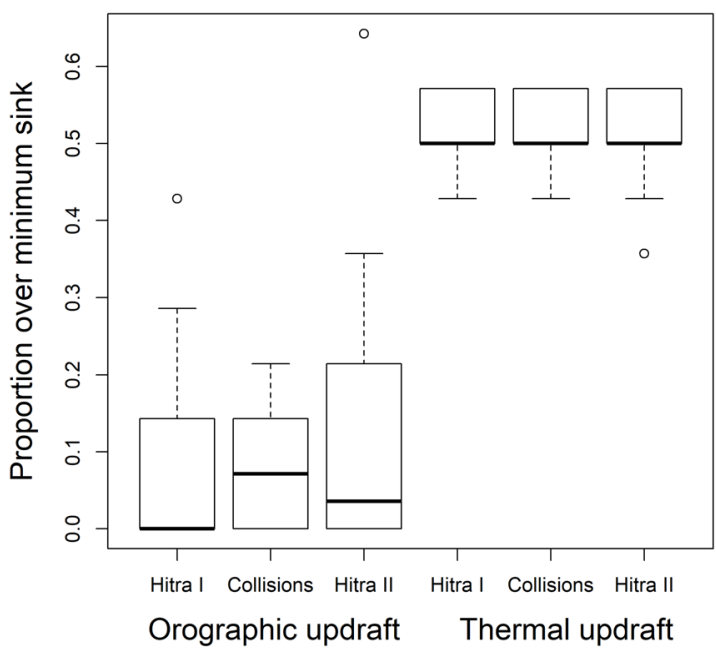

wind-turbine locations as well as recorded bird collisions on the island of Hitra, Norway. The boxplots show the median (black line), 75 (white box), and 95 (whiskers) percentiles

clouds) (Li et al. 2013; Tomlinson et al. 2011) at a fine spatial resolution it does not allow for a fine temporal resolution, capturing within-day variance in wind speed or radiation. However, for micrositing of wind turbines, the spatial resolution will be of highest importance. As illustrated in Fig. 1, these relatively small and fragmented orographic uplift patches along hills and ridges provide pockets with stronger orographic updraft velocities compared to the relatively weaker updraft velocities in the thermal uplift areas. The strongest orographic uplift is associated with strongly negative thermal uplift. This is because strong winds, which are required for orographic 
uplift, produce shear that tends to break apart thermal formation (Bohrer et al. 2012). The development, strength, and duration of thermal convection is affected by topography as well as changing atmospheric and environmental conditions (Shamoun-Baranes et al. 2003). While the highest levels of thermal uplift were widely found in flat terrain but temporally limited to calm and sunny days, the more commonly occurring orographic uplift was spatially limited to steep slopes and ridges. This clearly shows the importance for high-resolution modeling, as small pockets of strong orographic updrafts may not have been identified at coarser spatial resolutions. It should however be noted that this methodology should mainly be utilized as a spatial proxy to identify wind turbine sites with enhanced collision risk due to uplift conditions as it does not incorporates all environmental and meteorological variability of complex updraft landscapes (Bohrer et al. 2012; Dodge et al. 2014; Santos et al. 2017; Sapir et al. 2011).

From a methodological perspective, the importance of having temporally comparable and coincident climate parameters has to be emphasized, atmospheric correction parameters, and cloud-free images. For the seasonal study periods a total of 14 cloud-free Landsat 8 images were of acceptable quality. Although the small number of Landsat images considered limit the inferences for validation, for thermal updraft estimation at Hitra this was the only available cloud-free images at the spatial resolution of $100 \times 100 \mathrm{~m}$ of the Landsat 8 Thermal Band 10. Alternative temporal climate data, including interpolated raster grids on air temperature, wind speed, and wind direction from the Norwegian Meteorological Institute, are not meaningful for the rugged terrain of Hitra given their low spatial resolution $\left(1 \mathrm{~km}^{2}\right)$. As the Nordic hemisphere average solar declination angle from June to September is $15^{\circ} \mathrm{N}$ (Stull 1988), thermal updrafts have their optimum in northern midlatitudes (from $31^{\circ}$ to $59^{\circ} \mathrm{N}$ ) during spring into late summer (Bradbury 2000). It is therefore reasonable to expect relatively low thermal updraft velocities at the high latitude of Hitra $\left(63.60^{\circ} \mathrm{N}\right)$. In an identical study conducted in the Tarifa region at the Spanish side of the Gibraltar strait $\left(36.0132^{\circ} \mathrm{N}, 5.6027^{\circ} \mathrm{W}\right)$, Santos et al. (2017) estimated thermal updraft values for the same season about three times higher than the estimated maximum value for Hitra. Given that wind turbines once sited will operate at that specific location throughout the operational lifetime of the windpower plant, maximum updraft velocities form a good proxy potential risk of collision from a precautionary perspective. Even though this risk may not necessarily exceed the minimum sink rate for species of concern at all times, those situations will inevitably occur at such sites over time.

Soaring birds are known to use thermal and orographic uplift to gain altitude to save energy (Barrios and Rodriguez 2004; Harel et al. 2016a; Shamoun-Baranes et al.
2003, 2016). The updrafts generated at the topographic locations of wind turbines together with air diverted around the turbines may attract soaring bird species, enhancing collision risk (Barrios and Rodriguez 2004; de Lucas et al. 2012; Drewitt and Langston 2008; Krijgsveld et al. 2011). The validation of this approach at Hitra, as well as a similar study executed in Tarifa (Gibraltar, Spain) (Santos et al. 2017), indicated a significant correlation between the finescale distribution of especially orographic updrafts and raptor flight activity. White-tailed eagles preferred to utilize the relatively fragmented patches with strong orographic updraft velocities. Their probability of presence at locations with uplift depended on their flight altitude. Their response to orographic uplift was strongest at low flight altitudes; generally, within the range of the rotor swept zone. Contrary to this, the white-tailed eagles were not selecting the more widely distributed areas with weaker thermal updraft velocities. Katzner et al. (2012) found that golden eagles Aquila chrysaetos flew at lower altitudes over steep slopes and cliffs (where orographic lift can develop) compared to flights over flats and gentle slopes (where thermal lift is more likely). Santos et al. (2017) found that black kites Milvus migrans flew at lower altitudes above ground level during linear soaring compared to circling. This study also confirmed that white-tailed eagles flew higher at locations with higher thermal updraft velocities. Although the negative association with thermal uplift to the probability of presence may seem counterintuitive, the thermal updraft velocities never reached as high values as did orographic updraft. Most studies on soaring behavior fueled by uplift have been carried out at southern latitudes, where the thermal uplift component is much stronger than in Norway (Barrios and Rodriguez 2004; Harel et al. 2016a; ShamounBaranes et al. 2003, 2016; Treep et al. 2016). White-tailed eagles can therefore not be expected to actively seek out such areas at high latitudes. Even though white-tailed eagles are known to use circling flight at higher flight altitudes on calm, warm, and sunny days (pers. obs.), such days do not occur often at the northern latitudes of Hitra. Although such circumstances may allow for staying aloft over long periods with minimum expenditure of effort (Pennycuick), it will not be a reliable way for cross-country soaring. Linear soaring along steep slopes and ridges will provide whitetailed eagles with a much more efficient cross-country flight strategy during the more usual windy conditions. Ridge soaring can be operated at best glide speed, a more efficient condition than minimum sink speed. White-tailed eagles will unlikely be able to benefit from both types of uplift conditions given the strong negative correlation between areas (slopes versus flat terrain) and periods (windy and cloudy versus calm and sunny), where and when orographic versus thermal updrafts are strongest (cf. Santos et al. 2017). Still, to enable identifying temporal thermal 
"hotspots", choosing Landsat images on such days is warranted with regard to micrositing of wind turbines. The local patches of strong orographic updrafts providing low-flying soaring birds with the required uplift above the minimum sink speed will therefore be most important with regard to risk for collision.

The choice of placement of the wind turbines within the landscape can thus minimize the exposure of birds to the hazard posed by those wind turbines (May et al. 2015). This study indicated that the current and proposed turbines on the island of Hitra were sited at locations with maximum orographic updraft velocities around the minimum sink rate for white-tailed eagles. Still, the turbines were sited at locations with higher maximum thermal updraft velocities potentially leading to temporal exposure to increased collision risk on warm and sunny days. Developers typically seek to locate turbines, where wind conditions and inter-turbine spacing are optimized with respect to wind capture and minimized wake effects (Herbert-Acero et al. 2014; Serrano González et al. 2014). Wind turbines are often sited on hilltops or along ridges where they are well-exposed to prevailing winds from all directions, and where wind speeds are higher due to upward compression (caused by the Venturi or Bernoulli effect) on the windward side of the topography (Whiteman 2000). These upward, orographic, air currents are the same which are utilized by soaring birds to gain altitude (Katzner et al. 2012; Miller et al. 2014). This causes a trade-off situation for micrositing of wind turbines between birdattractive updraft locations and locations attractive for wind yield. However, having access to (proxy) information on both - potentially conflicting - aspects during the design phase, enables developers to make a trade-off decision minimizing the potential collision risk per $\mathrm{kWh}$ when micrositing wind turbines (Bohrer et al. 2013; Liechti et al. 2013). Micrositing has so far been proposed in agricultural areas (Mammen et al. 2011) and wetlands (Hill et al. 2011), and especially along ridges with many soaring and migratory raptors (Barrios and Rodriguez 2004; de Lucas et al. 2012; Katzner et al. 2012; Kitano and Shiraki 2013; Smallwood and Thelander 2008). Although proposed by several, it remains unclear whether micrositing practice has resulted in adjusted design of windpower plants. This is probably because it is mainly promoted as part of the project-by-project consenting process and mitigation requirements, and not (yet) integrated into standard wind project design and optimization software (e.g., Openwind, WindFarmer, and WindPro) such as noise, visibility, and shadow flickering (Herbert-Acero et al. 2014; Serrano González et al. 2014). Forecasting landscape features that enhance potential risk for soaring raptors could, however, be implemented cost-effectively in the pre-construction assessment for improved micrositing of wind turbines to reduce environmental impacts and associated economic risk.

\section{Conclusion}

This study presents a cost-effective high-resolution orographic and thermal updraft modeling tool, based on a combination of GIS and remote sensing imagery, for the identification of riskenhancing landscape features that can be used to predict the probability of presence of soaring raptors. The validation of this tool, performed at Hitra and in Tarifa (Gibraltar, Spain) (Santos et al. 2017), indicated a significant correlation between the fine-scale distribution of especially orographic updrafts and GPS-tracked raptor flight activity. The developed tool is easy to implement anywhere using publicly available high-resolution digital terrain models and cloud-free satellite imagery. Moreover, the method is flexible with respect to the local availability of climate parameters and atmospheric correction parameters as well as the bird species considered. This study may contribute to improved preconstruction assessment of wind-power plants through "bird-friendly" micrositing of wind turbines, and hence reduce the environmental impacts for soaring raptors.

\section{Data availability}

All Landsat 8 imagery for the validation are available from USGS Earth Explorer (https://earthexplorer.usgs.gov/). The DTM10 for the validation is supplied as supplementary materials at NINAs geodata portal (https:/geodata.nina.no/ layers/geonode:dem10utm). All image acquisition dates, and atmospheric and climatic constants are listed in Table 1 in the submitted manuscript.

\section{Code availability}

Codes for the updraft calculations are supplied as supplementary materials at NINAs GitHUB repository (https:// github.com/NINAnor/INTACT_Micrositing). The R scripts and data files to perform the white-tailed eagle validation are supplied as supplementary materials at the Mendeley Data repository (https://doi.org/10.17632/pkbsnftv5h.1).

Acknowledgements We would like to thank the co-funders of the INTACT project Statkraft, Statoil, Vattenfall, Water Resources and Energy Directorate, Energy Norway and TrønderEnergi Kraft for their support. We would also like to thank Dr. Jakub Walawender and his team at the Polish National Research Institute for sharing the ArcGIS toolset for automated mapping of land surface temperature from Landsat 8 data. Finally, we would also like to thank Professor Jan Ketil $\mathrm{R} \varnothing \mathrm{d}$ at NTNU for reviewing the manuscript before submission, and two anonymous reviewers after submission. Open Access funding provided by Norwegian institute for nature research.

Funding This study was performed as part of the R\&D project "Innovative Mitigation Tools for Avian Conflicts with wind Turbines" (INTACT) (co-)funded by the Research Council of Norway (grant number 226241). 
Author Contributions All authors contributed to the study conception and design. Material preparation, data collection, and analysis were performed by FH (GIS modeling), TN (GPS data), and RM (statistical analyses). The first draft of the manuscript was written by RM and FH and all authors commented on previous versions of the manuscript. All authors read and approved the final manuscript.

\section{Compliance with Ethical Standards}

Conflict of Interest The authors declare that they have no conflict of interest.

Publisher's note Springer Nature remains neutral with regard to jurisdictional claims in published maps and institutional affiliations.

Open Access This article is licensed under a Creative Commons Attribution 4.0 International License, which permits use, sharing, adaptation, distribution and reproduction in any medium or format, as long as you give appropriate credit to the original author(s) and the source, provide a link to the Creative Commons license, and indicate if changes were made. The images or other third party material in this article are included in the article's Creative Commons license, unless indicated otherwise in a credit line to the material. If material is not included in the article's Creative Commons license and your intended use is not permitted by statutory regulation or exceeds the permitted use, you will need to obtain permission directly from the copyright holder. To view a copy of this license, visit http://creativecommons. org/licenses/by/4.0/.

\section{References}

Allen RG, Pereira LS, Raes D, Smith M (1998) Crop evapotranspiration: Guidelines for computing crop water requirements. Food and Agriculture Organization of the United Nations, Rome

Barrios L, Rodriguez A (2004) Behavioural and environmental correlates of soaring-bird mortality at on-shore wind turbines. J Appl Ecol 41:72-81. https://doi.org/10.1111/j.1365-2664.2004.00876.x

Barrios L, Rodriguez A (2007) Spatiotemporal patterns of bird mortality at two wind farms of Southern Spain. In: de Lucas M, Janss GFE, Ferrer M (eds) Birds and Wind Farms. Risk Assessment and Mitigation. vol 13. Servicios Informativos Ambientales/ Quercus, Madrid, p 229-239

Barsi JA, Barker JL, Schott JR (2003) An atmospheric correction parameter calculator for a single thermal band earth-sensing instrument. IGARSS03, Centre de Congres Pierre Baudis, Toulouse. 21-25 July 2003

Barsi JA, Schott JR, Palluconi FD, Hook SJ (2005) Validation of a web-based atmospheric correction tool for single thermal band instruments In: Earth observing systems X. SPIE Proceedings 5882. https://doi.org/10.1117/12.619990

Bates D, Maechler M, Bolker B, Walker S (2015) Fitting linear mixedeffects models using lme4. J Stat Softw 67:1-48. https://doi.org/ 10.18637/jss.v067.i01

Berg LK, Newsom RK, Turner DD (2017) Year-long vertical velocity statistics derived from Doppler Lidar data for the continental convective boundary layer. J Appl Meteorol Climatol 56:2441-2454. https://doi.org/10.1175/jamc-d-16-0359.1

Bohrer G et al. (2012) Estimating updraft velocity components over large spatial scales: contrasting migration strategies of golden eagles and turkey vultures. Ecol Lett 15:96-103. https://doi.org/ 10.1111/j.1461-0248.2011.01713.x
Bohrer G, Zhu K, Jones RL, Curtis PS (2013) Optimizing wind power generation while minimizing wildlife impacts in an urban area. PLoS ONE 8:e56036. https://doi.org/10.1371/journal.pone. 0056036

Borak RDP, Devadiga JS, Wolfe S, Zheng REM, Descloitres J (2002) The MODIS land product quality assessment approach. Remote Sens Environ 83:62-76

Bradbury T (2000) Meteorology and Flight: A Pilots Guide to Weather. A\&C Black. London. 186p

Brandes D, Ombalski DW (2004) Modeling raptor migration pathways using a fluid-flow analogy. J Raptor Res 38:195-207

Dahl EL, Bevanger K, Nygård T, Røskaft E, Stokke BG (2012) Reduced breeding success in white-tailed eagles at Smøla windfarm, western Norway, is caused by mortality and displacement. Biol Conserv 145:79-85. https://doi.org/10.1016/j.biocon.2011. 10.012

Dahl EL, May R, Hoel PL, Bevanger K, Pedersen HC, Røskaft E, Stokke BG (2013) White-tailed eagle (Haliaeetus albicilla) at the Smøla wind-power plant, central Norway, lack behavioral flight responses to wind turbines. Wildl Soc Bull 37:66-74

de Lucas M, Ferrer M, Janss GF (2012) Using wind tunnels to predict bird mortality in wind farms: the case of griffon vultures. PLoS ONE 7:e48092. https://doi.org/10.1371/journal.pone.0048092

de Lucas M, Janss GFE, Whitfield DP, Ferrer M (2008) Collision fatality of raptors in wind farms does not depend on raptor abundance. J Appl Ecol 45:1695-1703. https://doi.org/10.1111/j. 1365-2664.2008.01549.x

De Wekker SFJ, Kossmann M (2015) Convective boundary layer heights over mountainous terrain-a review of concepts frontiers in earth science. Front Earth Sci. https://doi.org/10.3389/feart. 2015.00077

Dodge S et al. (2014) Environmental drivers of variability in the movement ecology of turkey vultures (Cathartes aura) in North and South America. Philos Trans R Soc Lond Ser B 369:20130195. https://doi.org/10.1098/rstb.2013.0195

Drewitt AL, Langston RH (2008) Collision effects of wind-power generators and other obstacles on birds. Ann N Y Acad Sci 1134:233-266. https://doi.org/10.1196/annals.1439.015

Duerr AE et al. (2012) Testing an emerging paradigm in migration ecology shows surprising differences in efficiency between flight modes. PLoS ONE 7:e35548. https://doi.org/10.1371/journal. pone. 0035548

Ferrer M, de Lucas M, Janss GFE, Casado E, Munoz AR, Bechard MJ, Calabuig CP (2012) Weak relationship between risk assessment studies and recorded mortality in wind farms. J Appl Ecol 49:38-46. https://doi.org/10.1111/j.1365-2664.2011.02054.x

Harel R et al. (2016a) Decision-making by a soaring bird: time, energy and risk considerations at different spatio-temporal scales. Philos Trans R Soc Lond Ser B 371:20150397. https://doi.org/10.1098/ rstb.2015.0397

Harel R, Horvitz N, Nathan R (2016b) Adult vultures outperform juveniles in challenging thermal soaring conditions. Sci Rep 6:27865. https://doi.org/10.1038/srep27865

Hedenström A, Alerstam T (1995) Optimal flight speed of birds. Philos Trans R Soc Lond B 348:471-487

Herbert-Acero J, Probst O, Réthoré P-E, Larsen G, Castillo-Villar K (2014) A review of methodological approaches for the design and optimization of wind farms. Energies 7:6930-7016. https://doi. org/10.3390/en7116930

Hill R, du Gueschlin P, Herring M, McCarthy M, Smales I (2011) Managing cumulative wind farm impacts on the Brolga Grus rubicunda in Victoria, Australia. Proceedings paper presented at the Conference on Wind energy and Wildlife impacts, 2-5 May 2011. Norwegian Institute for Nature Research, Trondheim 
Hu ZL, Islam S, Jiang L (1999) Approaches for aggregating heterogeneous surface parameters and fluxes for mesoscale and climate models. Bound Layer Meteorol 93:313-336

Jenkins AR, van Rooyen CS, Smallie JJ, Harrison JA, Smit-Robinson HA, Ralston S (2015) Birds and wind-energy best-practice guidelines: best practice guidelines for avian monitoring and impact mitigation at proposed wind energy development sites in southern Africa, 3rd edn. The Endangered Wildlife Trust and BirdLife South Africa, Johannesburg

Katzner TE et al. (2012) Topography drives migratory flight altitude of golden eagles: implications for on-shore wind energy development. J Appl Ecol 49:1178-1186. https://doi.org/10.1111/j.13652664.2012.02185.x

Kitano M, Shiraki S (2013) Estimation of bird fatalities at wind farms with complex topography and vegetation in Hokkaido, Japan Wildl Soc Bull 37:41-48. https://doi.org/10.1002/wsb.255

Krijgsveld KL et al. (2011) Effect studies offshore wind farm Egmond aan Zee. Final report on fluxes, flight altitudes and behaviour of flying bird. Bureau Waardenburg, Culemborg

Langston RHW (2013) Birds and wind projects across the pond: a UK perspective. Wildl Soc Bull 37:5-18. https://doi.org/10.1002/w sb. 262

LeDell E, Petersen M, van der Laan M (2015) Computationally efficient confidence intervals for cross-validated area under the ROC curve estimates. Electron J Statist 9:1583-1607. https://doi.org/ 10.1214/15-EJS1035

Li Z-L et al. (2013) Satellite-derived land surface temperature: current status and perspectives. Remote Sens Environ 131:14-37. https:// doi.org/10.1016/j.rse.2012.12.008

Liechti F, Guelat J, Komenda-Zehnder S (2013) Modelling the spatial concentrations of bird migration to assess conflicts with wind turbines. Biol Conserv 162:24-32. https://doi.org/10.1016/j. biocon.2013.03.018

Mammen U, Mammen K, Heinrichs N, Resetaritz A (2011) Red kite (Milvus milvus) fatalities at wind turbines-why do they occur and how they are to prevent? Paper presented at the proceedings conference on wind energy and Wildlife impacts, Trondheim. 2-5 May 2011

Marques AT et al. (2014) Understanding bird collisions at wind farms: an updated review on the causes and possible mitigation strategies. Biol Conserv 179:40-52. https://doi.org/10.1016/j.biocon. 2014.08.017

May R (2017) Mitigation options for birds. In: Perrow M (ed) Wildlife and windfarms: conflicts and solutions, vol 2. Onshore Solutions, Pelagic Publishing, Exeter p 124-145

May R, Nygård T, Dahl EL, Bevanger K (2013) Habitat utilization in white-tailed eagles (Haliaeetus albicilla) and the displacement impact of the Smøla wind-power plant. Wildl Soc Bull 37:75-83. https://doi.org/10.1002/wsb.264

May R, Reitan O, Bevanger K, Lorentsen SH, Nygard T (2015) Mitigating wind-turbine induced avian mortality: sensory, aerodynamic and cognitive constraints and options. Renew Sust Energ Rev 42:170-181. https://doi.org/10.1016/j.rser.2014.10.002

Mellone U et al. (2012) Interspecific comparison of the performance of soaring migrants in relation to morphology, meteorological conditions and migration strategies. PLoS ONE 7:e39833. https://doi. org/10.1371/journal.pone.0039833

Miller TA et al. (2014) Assessing risk to birds from industrial wind energy development via paired resource selection models. Conserv Biol 28:745-755. https://doi.org/10.1111/cobi.12227

Norwegian Meteorological Survey (2017) Norwegian Meteorological Survey. http://sharki.oslo.dnmi.no/portal/page?_pageid=73,39035,73_ 39049\&_dad=portal\&_schema=PORTAL. Accessed 01 Jan 2017
Nygård T et al. (2010) Research on white-tailed Eagles at Smøla windpower plant. In: BOU conference on climate change and birds. British Ornithologists' Union (BOU), Leicester. p 1-4

Pennycuick CJ (2008) Modelling the flying bird. Elsevier, London

Poessel SA, Duerr AE, Hall JC, Braham MA, Katzner TE, Minderman $\mathbf{J}$ (2018) Improving estimation of flight altitude in wildlife telemetry studies. J Appl Ecol 55:2064-2070. https://doi.org/10. $1111 / 1365-2664.13135$

R Core Team (2015) R: a language and environment for statistical computing, 3.2.2 edn. R Foundation for Statistical Computing, Vienna

Ralston Paton S et al. (2017) Wind energy's impacts on birds in South Africa: a preliminary review of the results of operational monitoring at the first wind farms of the Renewable Energy Independent Power Producer Procurement Programme in South Africa. BirdLife South Africa, Johannesburg

Reddy G, Celani A, Sejnowski TJ, Vergassola M (2016) Learning to soar in turbulent environments. Proc Natl Acad Sci USA 113: E4877-4884. https://doi.org/10.1073/pnas.1606075113

Santos CD, Hanssen F, Muñoz A-R, Onrubia A, Wikelski M, May R, Silva JP (2017) Match between soaring modes of black kites and the fine-scale distribution of updrafts. Sci Rep 7:6421

Sapir N, Horvitz N, Wikelski M, Avissar R, Mahrer Y, Nathan R (2011) Migration by soaring or flapping: numerical atmospheric simulations reveal that turbulence kinetic energy dictates beeeater flight mode. Proc R Soc B 278:3380-3386

Scacco M, Flack A, Duriez O, Wikelski M, Safi K (2019) Static landscape features predict uplift locations for soaring birds across Europe. R Soc Open Sci 6:181440. https://doi.org/10.1098/rsos.181440

Schuster E, Bulling L, Koppel J (2015) Consolidating the state of knowledge: a synoptical review of wind energy's wildlife effects. Environ Manag 56:300-331. https://doi.org/10.1007/s00267-015-0501-5

Serrano González J, Burgos Payán M, Santos JMR, González-Longatt F (2014) A review and recent developments in the optimal windturbine micro-siting problem. Renew Sust Energ Rev 30:133-144. https://doi.org/10.1016/j.rser.2013.09.027

Shamoun-Baranes J, Bouten W, van Loon EE, Meijer C, Camphuysen CJ (2016) Flap or soar? How a flight generalist responds to its aerial environment. Philos Trans $\mathrm{R}$ Soc Lond Ser B 371:20150395. https://doi.org/10.1098/rstb.2015.0395

Shamoun-Baranes J, Leshem Y, Yom-Tov Y, Liechti O (2003) Differential use of thermal convection by soaring birds over central Israel. Condor 105:208-218. https://doi.org/10.1650/0010-5422 (2003)105[0208:Duotcb]2.0.Co;2

Shannon HD, Young GS, Yates MA, Fuller MR, Seegar WS (2003) Measurements of thermal updraft intensity over complex terrain using American white pelicans and a simple boundary-layer forecast model. Bound Layer Meteorol 104:167-199

Shepard EL, Williamson C, Windsor SP (2016) Fine-scale flight strategies of gulls in urban airflows indicate risk and reward in city living. Philos Trans R Soc Lond Ser B 371:20150394. https:// doi.org/10.1098/rstb.2015.0394

Smallwood KS, Thelander C (2008) Bird mortality in the Altamont Pass Wind Resource Area, California. J Wildl Manag 72:215-223. https://doi.org/10.2193/2007-032

Stull RB (1988) An introduction to boundary layer meteorology, 1st edn. Kluwer Academic Publishers, Dordrecht

Tomlinson CJ, Chapman L, Thornes JE, Baker C (2011) Remote sensing land surface temperature for meteorology and climatology: a review. Meteorol Appl 18:296-306. https://doi.org/10.1002/met.287

Treep J, Bohrer G, Shamoun-Baranes J, Duriez O, Prata de Moraes Frasson R, Bouten W(2016) Using high-resolution GPS track data bird flight meteorological observations Bull Am Meteorol Soc 97:951-961. https://doi.org/10.1175/bams-d-14-00234.1 
United States Geological Survey (2017) United States Geological Survey. http://earthexplorer.usgs.gov. Accessed 01 Jan 2017

Vind SAE (2010) Konsesjonssøknad Hitra 2 vindpark. Del A. SAE Vind DA, Oslo

Walawender JP, Hajto MJ, Iwaniuk P (2012) A new ArcGIS toolset for automated mapping of land surface temperature with the use of LANDSAT satellite data. Paper presented at the international geoscience and remote sensing symposium (IGARSS), Munich. Institute of Electrical and Electronics Engineers (IEEE)
Wang SF, Wang SC, Smith P(2015) Ecological impacts of wind farms birds: quest, hypotheses, and research needs Renew Sustain Energy Rev 44:599-607. https://doi.org/10.1016/j.rser.2015.01.031

Watson RT et al. (2018) Raptor interactions with wind energy: case studies from around the world. J Raptor Res 52:1-18. https://doi. org/10.3356/jrr-16-100.1

Whiteman CD (2000) Mountain meteorology: fundamentals and applications. Oxford University Press, New York

Wiens TS, Dale BC, Boyce MS, Kershaw GP (2008) Three way k-fold cross-validation of resource selection functions. Ecol Model 212:244-255. https://doi.org/10.1016/j.ecolmodel.2007.10.005 